\title{
Sentencia del Tribunal Constitucional que declara inaplicable norma de la ley de ISAPRES y derechos económicos, sociales y culturales
}

Este comentario, junto a los documentos que analiza, está disponible en www.anuariocdh.uchile.cl

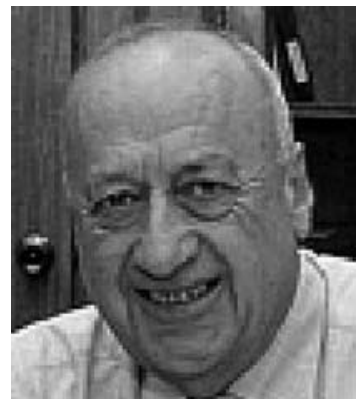

\section{Luis Bates}

Abogado de la Universidad de Chile. Doctor en Derecho Penal de la Universidad Complutense de Madrid, España. Profesor de Derecho en la Pontificia Universidad Católica, la Universidad Gabriela Mistral y la Universidad del Desarrollo. Ex Presidente del Consejo de Defensa del Estado de su país y ex ministro de Estado del Presidente Ricardo Lagos.

bates.luis@gmail.com

\section{RESUMEN}

El artículo analiza los principales antecedentes y las conclusiones que estableció el Tribunal Constitucional al resolver el requerimiento de inaplicabilidad por inconstitucionalidad de la Ley $N^{\circ} 18.933$, Ley de Instituciones de Salud Previsional. El requerimiento cuestiona la constitucionalidad de los preceptos que facultan a las Instituciones de Salud Previsional a aumentar el precio base de los contratos de salud aplicando la tabla de factores -particularmente la edad y el sexo-respecto de los derechos a la igualdad ante la ley, el derecho a la protección de la salud y el derecho de propiedad, garantizados en los numerandos $2^{\circ}, 9^{\circ}$ y 24 del artículo 19, respectivamente, de la Constitución Política de la República (CPR).

\section{El conflicto}

Durante el 2008, el Tribunal Constitucional (TC) debió resolver un recurso de inaplicabilidad por inconstitucionalidad del art. 38 ter de la Ley No 18.933, Ley de Instituciones de Salud Previsional (ISAPRES) ${ }^{1}$. Este requerimiento se enmarca en la presentación de un Recurso de Protección

\footnotetext{
1 "Artículo 38 ter.- Para determinar el precio que el afiliado deberá pagar a la Institución de Salud Previsional por el plan de salud, la Institución deberá aplicar a los precios base que resulten de lo dispuesto en el artículo precedente, el o los factores que correspondan a cada beneficiario, de acuerdo a la respectiva tabla de factores. La Superintendencia fijará, mediante instrucciones de general aplicación, la estructura de las tablas de factores, estableciendo los tipos de beneficiarios, según sexo y condición de cotizante o carga, y los rangos de edad que se deban utilizar. Cada rango de edad que fije la Superintendencia en las instrucciones señaladas en el inciso precedente se sujetará a las siguientes reglas: (1) El primer tramo comenzará desde el nacimiento y se extenderá hasta menos de dos años de edad; (2) Los siguientes tramos, desde los dos años de edad y hasta menos de ochenta años de edad, comprenderán un mínimo de tres años y un máximo de cinco años; (3) La Superintendencia fijará, desde los ochenta años de edad, el o los tramos que correspondan; (4) La Superintendencia deberá fijar, cada diez años, la relación máxima entre el factor más bajo y el más alto de cada tabla, diferenciada por sexo; (5) En cada tramo, el factor que corresponda a una carga no podrá ser superior al factor que corresponda a un cotizante del mismo sexo. En el marco de lo señalado en el inciso precedente, las Instituciones de Salud Previsional serán libres para determinar los factores de cada tabla que empleen. En todo caso, la tabla de un determinado plan de salud no podrá variar para los beneficiarios mientras se encuentren adscritos al mismo, ni podrá alterarse para quienes se incorporen a él, a menos que la modificación consista en disminuir de
} 
deducido en contra de una determinada ISAPRE en el cual la requirente impugnaba el aumento del precio de su plan de salud, el que se realizó conforme con la "Tabla de Factores" que considera, entre otros elementos, la edad y el sexo de las personas afiliadas al sistema de ISAPRES. Según la requirente el alza del precio base del plan de salud infringiría la regulación legal vigente en la materia y vulneraría las garantías constitucionales de igualdad ante la ley, el derecho a la protección de la salud y el derecho de propiedad, garantizados en los numerandos $2^{\circ}, 9^{\circ}$ y 24 del artículo 19, respectivamente, de la Constitución Política de la República (CPR).

Entre sus argumentos, la requirente señaló que el legislador autorizó a las ISAPRES a realizar distinciones en el trato arbitrarias en base a categorías como el sexo y la edad para aumentar los precios de los contratos en base.

Respecto del derecho a la protección de la salud, se argumentó que fue infringido pues el aumento de los precios de los contratos base de las ISAPRES sería una forma indirecta de obligar a salir del sistema privado de salud, lo que constituiría una barrera a la libertad de elección del sistema de salud y la igualdad de acceso al régimen escogido por el beneficiario al celebrar el respectivo contrato.

Finalmente, en relación al derecho de propiedad se señaló, por una parte, que permitir el aumento del precio de los planes por razones de edad privaría a la persona afectada del derecho a gozar del sistema privado de salud, el cual sería un derecho inmaterial susceptible de apreciación pecuniaria. Por otra, se indicó que "se impediría también a los afectados disfrutar de los beneficios que les otorga el respectivo plan de salud, los cuales se encuentran incorporados a su patrimonio, dejando a cada uno de ellos como cotizante cautivo, sin que se prevea la existencia de una contraprestación en beneficios, equivalente al aumento del precio referido" ${ }^{2}$.

\section{a. La defensa de la ISAPRE}

La ISAPRE recurrida argumentó que (a) como cuestión previa la inadmisibilidad del requerimiento ya que el precepto legal impugnado -art. 38 ter de la Ley de ISAPRES- no era decisivo para decidir el caso de fondo (Art. 93 de la CPR) porque no podía aplicarse a los contratos de salud suscritos con anterioridad a su entrada en vigencia (17 de mayo del año 2005), como ocurría en el caso de autos (la requirente contrató el año 1997. Posteriormente su contrato fue modificado en los años 1998 y 1999); (b) que conforme con la ley, la tabla de factores -entre ellos la edad y el sexo- se mantiene vigente hasta que el afiliado opte por aceptar un plan alternativo en que se le ofrezca alguna adecuación o hasta que contrate un plan de salud distinto, lo que no habría ocurrido en su caso. La ISAPRE indicó que conforme con lo dispuesto en el art. 38, inciso $5^{\circ}$ de la Ley $N^{\circ} 18.933$ modificado por la Ley $N^{\circ} 19.381$ de 1995, el alza del precio del plan de salud tiene su origen en la tabla de factores convencionalmente pactada antes de la entrada en vigencia del art. 38 ter, por lo que no tendría incidencia en el fallo del Recurso de Protección pendiente;

forma permanente los factores, total o parcialmente, lo que requerirá autorización previa de la Superintendencia; dicha disminución se hará aplicable a todos los planes de salud que utilicen esa tabla. Cada plan de salud sólo podrá tener incorporada una tabla de factores. Las Instituciones de Salud Previsional no podrán establecer más de dos tablas de factores para la totalidad de los planes de salud que se encuentren en comercialización. Sin perjuicio de lo dispuesto en el inciso precedente, las Instituciones de Salud Previsional podrán establecer nuevas tablas cada cinco años, contados desde las últimas informadas a la Superintendencia, manteniéndose vigentes las anteriores en los planes de salud que las hayan incorporado. Las Instituciones de Salud Previsional estarán obligadas a aplicar, desde el mes en que se cumpla la anualidad y de conformidad con la respectiva tabla, el aumento o la reducción de factor que corresponda a un beneficiario en razón de su edad, y a informar al cotizante respectivo mediante carta certificada expedida en la misma oportunidad a que se refiere el inciso tercero del artículo 38".

2 Tribunal Constitucional. Rol 976-07-INA. Sentencia de 26 de junio de 2008, p. 6. 
(c) que el contrato de salud se configura sobre la base de un régimen de seguro en virtud del cual el afiliado transfiere sus riesgos a la ISAPRE. Por lo que el legislador, al regular el método para determinar el precio a pagar por el plan de salud, realiza una estimación del riesgo asociado a determinados factores objetivos como la edad y el sexo.

Igualmente, la ISAPRE impugnó la contravención al derecho a la protección de la salud y la condición de "cotizante cautiva" que invocó la actora, porque se trataría de un planteamiento que requeriría un control abstracto de constitucionalidad, materia que estimaban no podía ser resuelta por el TC al resolver sobre el recurso de inaplicabilidad. Además se indicó que la recurrente no acreditó que sufriera una vulneración actual del derecho a optar por un sistema de salud determinado, por lo no se encontraba acreditada la infracción al derecho de propiedad. También señaló que el derecho a escoger un sistema de salud y su permanencia en él no está contemplado en el derecho a la protección de la salud. En último termino, la ISAPRE indicó que la requirente buscaba continuar obteniendo las prestaciones de salud que la Constitución asegura, sin cumplir con la obligación elemental de pagar el precio contractualmente pactado, el cual estimaban era un exigencia respetuosa de la Constitución y de la Ley en cuanto a la forma de determinar y calcular el monto pertinente.

\section{b. Informe de la Superintendencia de Salud}

Con motivo de la solicitud del Tribunal Constitucional, la Superintendencia de Salud emitió un informe donde, en síntesis, sostiene la constitucionalidad de las normas legales relativas a la tabla de factores prescrita en la ley vigente. Este organismo señaló que la consideración a priori del sexo y edad de los beneficiarios como un factor de riesgo obedecía a criterios objetivos y que, medidos en grandes conjuntos para inferir probabilidades, permitían determinar o predecir el mayor o menor riesgo de gasto de la industria pertinente, la cual opera en forma semejante a los seguros. Además, la condición de régimen de seguro del sistema la legislación no debía perder de vista el carácter privado de la relación entre los contratantes y la consiguiente posibilidad de lucro para la ISAPRE.

\section{La sentencia del Tribunal Constitucional}

La sentencia del TC se divide en los siguientes capítulos: (i) problema sometido a la decisión del Tribunal; (ii) carácter decisivo del precepto legal impugnado; (iii) inaplicabilidad y gestión pendiente; (iv) naturaleza del derecho a la protección de la salud; (v) supremacía sobre convenciones entre particulares; (vi) base constitucional del contrato de salud; (vii) resolución del requerimiento de autos. A continuación describiremos parte de lo señalado en estos capítulos.

\section{a. El problema sometido a la decisión del Tribunal}

En el capítulo problema sometido a la decisión del Tribunal, el TC recuerda la facultad que le otorga el artículo 93 inciso primero $N^{0} 6$ de la CPR, de declarar inaplicable un precepto legal "en cualquier gestión concreta que se siga ante un tribunal ordinario o especial, [que] resulte contraria a la Constitución" ${ }^{3}$, previa verificación de la existencia de una gestión pendiente, de que la ley impugnada sea decisiva para la resolución de un asunto y que la impugnación esté fundada razonablemente y cumpla con los requisitos legales. Relaciona la ley impugnada con el artículo $2^{\circ}$ de ese mismo texto legal que individualiza los grupos de materias que regulan dicho artículo 38 ter impugnado: ISAPRES, Superintendencia de Salud y Planes de Salud.

3 Tribunal Constitucional. Rol 976-07-INA. Sentencia de 26 de junio de 2008, p. 15. 
A continuación, la sentencia se refiere a la determinación del costo del plan de salud contratado por un cotizante singular, el rol que le corresponde a la Superintendencia de Salud en la fijación de los factores y la estructura de las tablas en la fijación de los costos de los planes y la aplicación que de éstos se hizo en el caso sublite.

\section{b. Carácter decisivo del precepto legal impugnado}

En relación con la defensa de la ISAPRE sobre la supuesta falta de carácter decisivo del precepto impugnado para el caso concreto -pues este no sería aplicable al contrato de salud de la requirente-, el TC concluyó que esta era una materia que versaba sobre "cuestiones de mera legalidad, relacionadas con la vigencia de la ley en el tiempo, cuyo esclarecimiento no se halla dentro de la órbita de atribuciones de esta Magistratura, razón que resulta suficiente para desestimar lo alegado por la requerida" ${ }^{4}$.

\section{c. Inaplicabilidad y gestión pendiente}

En el capítulo inaplicabilidad y gestión pendiente, el TC señala que el requerimiento de inaplicabilidad constituye un control concreto de constitucionalidad. Al efecto, compara el actual recurso de inaplicabilidad con el recurso previsto en la CPR antes de la reforma del año 2005, e indicó que el antiguo recurso de inaplicabilidad facultaba a la Corte Suprema para realizar una "confrontación directa entre la norma legal y la disposición constitucional" y que "ahora se está en presencia de una situación diferente, por cuanto lo que podrá ser declarado inconstitucional, por motivos de forma o de fondo, es la aplicación del precepto legal impugnado a un caso concreto, como se dijo, lo que relativiza el examen abstracto de constitucionalidad, marcando así una clara diferencia con la regulación prevista por el texto constitucional anterior ${ }^{\prime \prime}$. A continuación el Tribunal, enfatizando el carácter concreto, no abstracto y acotado al caso describe y pondera los hechos y rasgos del requerimiento: la condición de mujer de la requirente que cumplió sesenta años de edad; afiliada desde 1997 a la ISAPRE requerida; describe las modificaciones del precio y la cobertura de los beneficios del plan de salud; las comunicaciones que se verificaron entre las partes y el recurso de protección que constituye la gestión pendiente que origina el requerimiento.

\section{d. Naturaleza del derecho a la protección de la salud}

EI TC señala que "de la dignidad que singulariza a toda persona humana se deriva un cúmulo de atributos, con los que nace y que conserva durante toda su vida" ${ }^{6}$. Añade que el sistema constitucional chileno se articula en torno a la dignidad de las personas, la cual operaría como fuente de derechos fundamentales preexistentes a la Constitución. Entre estos derechos se encontraría la protección a la salud y la servicialidad del Estado (Art. $1^{\circ} \mathrm{CPR}$ ), los cuales, conforme con el inciso $2^{\circ}$ del artículo $5^{\circ}$ de la CPR, requieren del respeto, protección y promoción tanto de organismos públicos como privados.

En los considerandos vigésimo sexto y siguientes, el TC invoca la doctrina y su propia jurisprudencia para afirmar que los derechos sociales son derechos de igual forma que lo son los derechos civiles y políticos y que por tanto no son "simples declaraciones o meras expectativas, cuya materialización efectiva quede suspendida hasta que las disponibilidades presupuestarias

4 Tribunal Constitucional. Rol 976-07-INA. Sentencia de 26 de junio de 2008, p. 23.

Tribunal Constitucional. Rol 976-07-INA. Sentencia de 26 de junio de 2008, p. 24.

Tribunal Constitucional. Rol 976-07-INA. Sentencia de 26 de junio de 2008, considerando vigésimo tercero, p. 28. 
del Estado puedan Ilevarlos a la práctica" ${ }^{\prime 7}$. Particularmente respecto del derecho a la protección de la salud se señala que:

"es de índole social, involucrando conductas activas de los órganos estatales y de los particulares para materializarlo en la práctica, habida consideración que la satisfacción de tal exigencia representa un rasgo distintivo de la legitimidad sustantiva del Estado Social en la democracia constitucional contemporánea"8.

Sobre la obligación del Estado y los particulares de respetar y promover los derechos constitucionales a la dignidad de la persona humana, el considerando trigésimo cuarto de la sentencia señala:

"Que, aplicando dicho criterio de hermenéutica constitucional y siendo la Carta Fundamental un sistema orgánico y coherente de valores, principios y normas, todos los cuales guardan entre sí correspondencia y armonía, excluyendo cualquiera interpretación que anule o prive de eficacia a algún precepto de ella, cabe insistir en que no sólo los órganos del Estado deben respetar y promover los derechos consustanciales a la dignidad de la persona humana, sino que esa obligación recae también en los particulares, aunque sea subsidiariamente, puesto que el Código Supremo asegura la intangibilidad de tales atributos en toda circunstancia, cualesquiera sean los sujetos que se hallen en la necesidad de infundir vigencia efectiva a lo proclamado en sus precepto".

EI TC reflexiona sobre los principios jurídicos de la subsidiariedad, la contribución de los particulares al bien común, la función social de propiedad, la afectación en su esencia de los derechos fundamentales y la interpretación y aplicación de las normas que regulan los contratos de salud. Al respecto, se señala en la sentencia que estos deben ser interpretados y aplicados "en términos de maximizar el disfrute real y pleno de los derechos que son consustanciales a la dignidad humana, entre ellos, el derecho social relativo a la protección de la salud, deben ser hechas a la luz de la maximización del disfrute real y pleno de los derechos constitucionales a la dignidad de las personas" ${ }^{\prime 9}$.

\section{e. Supremacía sobre convenciones entre particulares}

El Tribunal señala que los particulares tienen el deber de respetar y promover los derechos inherentes a la dignidad de la persona en las relaciones convencionales entre privados. Luego, el principio civilista de la autonomía de la voluntad cede ante la dignidad de la persona y la imposibilidad constitucional de afectar los derechos en su esencia, por lo que no resultan constitucionalmente válidas las cláusulas que puedan desconocer o aminorar tales derechos.

\section{f. Base constitucional del contrato de salud}

EI TC señala que, a pesar de su carácter privado, "el contrato de salud se erige y desenvuelve sobre una base cierta de jerarquía constitucional y de orden público, cualidades que presuponen su incorporación y vigencia en toda convención de esa especie". Por tanto, los contratos de salud se insertan en un contexto constitucional que determina un orden público irrenunciable.

Tribunal Constitucional. Rol 976-07-INA. Sentencia de 26 de junio de 2008, considerando vigésimo sexto, p. 29.

8 Tribunal Constitucional. Rol 976-07-INA. Sentencia de 26 de junio de 2008, considerando vigésimo noveno, p. 31.

9 Tribunal Constitucional. Rol 976-07-INA. Sentencia de 26 de junio de 2008, considerando trigésimo noveno, p. 36. 


\section{g. Resolución del requerimiento}

En este apartado el TC analiza el mérito legal y administrativo de la regulación y el procedimiento aplicable para determinar el precio de los planes de salud en razón de la edad conforme con la tabla de factores.

En la sentencia se señala que las ISAPRES deben respetar las exigencias del orden público constitucional relativo al derecho a la protección de la salud, lo cual incluye "el derecho a la libre elección del sistema de salud, público o privado, al que ella resuelva acogerse" ${ }^{\prime 10}$.

El TC objeta la magnitud del alza del costo del Plan de Salud según la Tabla de Factores, "justificada en cuanto a su existencia en condiciones objetivas y generales de riesgo", por estimar que ésta desconoce los principios de proporcionalidad de las prestaciones, maximización del goce del derecho a la protección de la salud, no discriminación y lesión a la esencia de la igualdad entre las partes.

Se afirma enseguida que la ley cuestionada -art. 38 ter de la Ley de ISAPRE- "puede ser constitucionalmente irreprochable en abstracto pero que, confrontado con tales hechos específicos, resulta patente su pugna con lo asegurado en la Carta Fundamental".

La sentencia de mayoría concluye acoger el requerimiento en cuanto a que la Tabla de Factores contemplada en el artículo 38 ter de la Ley de ISAPRES incorporada al contrato de salud de la requirente para determinar el costo de su Plan de Salud es inaplicable en la causa de origen "por ser contraria a cuanto le asegura el artículo 19 № 9 de la Constitución".

\section{h. Los votos disidentes}

Tres Ministros del TC estuvieron por desestimar el requerimiento. Indicaron que la ley impugnada consagra el derecho de las ISAPRES de fijar o incrementar unilateralmente el valor de sus planes de salud, al mismo tiempo que regula y restringe el ejercicio de este derecho dentro de los márgenes que la propia ley regula. Para los disidentes, esa alteración unilateral y reglada no es contraria a la Constitución pues ésta no prohíbe que la ley faculte la modificación unilateral del precio de un contrato dentro de ciertos márgenes establecidos por el propio legislador.

A mayor abundamiento, agregan que acoger el requerimiento implicaría alterar un contrato libremente pactado, modificando el precio establecido por una de las partes en conformidad a la ley, lo que afectaría el derecho de propiedad de los contratantes y la certeza jurídica.

Finalmente, un Ministro estuvo por desechar el requerimiento solo porque la ley impugnada no era parte de la relación contractual que ligó a las partes y no revistió el carácter de decisoriolitis. Agrega que la actuación de la ISAPRE debe ser soberanamente resuelta por el tribunal que conoce de la acción de protección.

\section{Comentario}

La estrecha votación de mayoría del fallo, los fundamentos del voto de los Ministros disidentes y el voto separado de uno de ellos, son prueba del carácter altamente debatible de lo resuelto por el TC.

10 Tribunal Constitucional. Rol 976-07-INA. Sentencia de 26 de junio de 2008, considerando quincuagésimo noveno, p. 44. 
A través del tiempo los derechos económicos, sociales y culturales han sido objeto de abundante literatura, así como de convenciones y tratados internacionales. Su diferenciación con los derechos civiles y políticos respecto a sus posibilidades de realización ha tenido, en nuestra opinión, una evolución que va desde una clara dependencia de la organización y recursos disponibles de cada Estado para la satisfacción de los mismos -sin imponer por lo tanto obligaciones jurídicas-, hasta su carácter obligatorio para el Estado y sus funcionarios, tendencia que representa el fallo que se comenta. Conforme con este desarrollo, tanto los derechos económicos, sociales y culturales, como los derechos civiles y políticos, son derechos humanos universales, indivisibles e interdependientes y están relacionados entre sí, debiendo ser tratados en forma global, en pie de igualdad y dándole a todos el mismo peso. Por tanto, la obligación de los Estados de respetar y promover los derechos fundamentales, incluidos los derechos sociales. Esta interpretación de "avanzada" tiende a garantizar a las personas el derecho a tener niveles mínimos de subsistencia digna, lo que se traduce en obligaciones especiales que los Estados se comprometen a respetar. En esta perspectiva, puede razonarse que ese nivel mínimo a los servicios de salud está suficientemente garantizado por el Estado de Chile mediante sus sistemas públicos y privados sin que se adviertan atisbos de regresividad en lo que se refiere a atención de salud básica.

El aspecto más polémico de la sentencia del TC radica en su extensión al sector privado de salud. El profesor Hugo Llanos ${ }^{11}$ ilustra esta materia del modo siguiente:

"Aunque la plena efectividad de estos derechos reconocidos en el Pacto, según algunos se logra progresivamente, 'la aplicación de algunos de estos derechos puede hacerse justiciable de inmediato, mientras otros derechos pueden hacerse justiciables con el paso del tiempo'.

Los estados partes deben rendir cuentas ante la comunidad internacional y ante sus propios pueblos con respecto al cumplimiento de sus obligaciones bajo el Pacto.

El Comité de Derechos Económicos, Sociales y Culturales, al considerar los informes de los Estados partes, deberían analizar las causas y los factores que obstaculizan la realización de los derechos consagrados con el Pacto y, hasta donde sea posible, señalar conclusiones.

Debido a que la realización progresiva de los derechos estipulados en el Pacto es relevante para el desarrollo, se debería dar especial atención a la adopción de medidas para mejorar el nivel de vida de los pobres y otros grupos desfavorecidos, teniendo en cuenta la posible necesidad de adoptar medidas para proteger los derechos culturales de los pueblos indígenas y las minorías.

Es cierto que los Derechos Civiles y Políticos han merecido mayor consideración por la comunidad internacional. Es así que a menudo se ha considerado que los DESCs son derechos de segunda clase, inaplicables, no sometidos a los tribunales ya que sólo se pueden hacer efectivos 'en forma progresiva', durante un tiempo que no se determina con precisión.

Pero ello es un error, ya que en modo alguno los DESCs son menos relevantes que los derechos civiles y políticos, y hoy día son objeto de una consideración preferente".

Agrega que,

“Un elemento de la obligación de proteger es la responsabilidad del Estado de asegurar que entidades privadas o particulares, incluidas las empresas transnacionales sobre las cuales ejerce jurisdicción, no violen los derechos económicos, sociales y culturales de las personas. Los Estados son respon-

11 LLANOS, H. Teoría y práctica del Derecho Internacional Público. La persona humana ante el Derecho Internacional. Tomo III. Tercera Edición, pp. 218 y ss. 
sables de las violaciones a los derechos económicos, sociales y culturales que resultan cuando no controlan con la debida diligencia la conducta de dichos actores no estatales.

Las obligaciones de los Estados de proteger los derechos económicos, sociales y culturales incluyen también su participación en organizaciones internacionales en las cuales actúan colectivamente".

Para concluir en otro pasaje de la obra referida al "disfrute del más alto nivel posible de salud" que:

"La realización progresiva del derecho a la salud a lo largo de un determinado período no debe interpretarse en el sentido de que priva de todo contenido significativo las obligaciones de los Estados partes. Antes, al contrario, la realización progresiva significa que los Estados partes tienen la obligación concreta y constante de avanzar lo más expedita y eficazmente posible hacia la plena realización del artículo 12 .

Al igual que en el caso de los demás derechos enunciados en el Pacto, existe una fuerte presunción de que no son permisibles las medidas regresivas adoptadas en relación con el derecho a la salud".

En nuestra opinión, los antecedentes de hecho y de derecho de la sentencia del TC permiten concluir que en el contexto de los cargos y rasgos propios del derecho a la protección de la salud el Estado de Chile ha avanzado de manera expedita y eficaz en las últimas décadas en las condiciones básicas de salud de la población y ha controlado con la debida diligencia, mediante la ley y los órganos que la ejecutan, los comportamientos de los actores no estatales. Los antecedentes de la causa en que incide la sentencia que se comenta son prueba de lo afirmado.

Aplicar idénticos criterios de exigibilidad al Estado y los particulares en el respeto y promoción del derecho a la protección de la salud es desconocer el rol y las características de uno y otro, y puede conducir a la falta de certeza jurídica y fáctica, cuyas consecuencias serían imprevisibles.

Por otra parte, las consideraciones del fallo de mayoría sobre la magnitud del alza de los precios de los planes de salud introducen, en nuestra opinión, un elemento de duda si se relaciona con lo resolutivo del mismo.

Deseable sería, por último, que las sentencias del TC por su importancia en la vida del país fueren menos extensas, más focalizadas y escritas con un lenguaje, en lo posible, al alcance del ciudadano(a) común. 